\title{
カラードプラ法を用いた胎児前大脳動脈， 中大脳動脈および後大巡動脈の血流動態に関する研究
}

\author{
秦 幸吉, 横原 研, 秦 利之, 北尾 学 \\ 島根医科大学医学部産科婦人科
}

\section{Fetal Cerebral Anterior, Middle and Posterior Arterial Hemodynamics Assessed by Color and Pulsed Doppler Ultrasound}

\author{
Kohkichi HATA, M.D., Ken MAKIHARA, M.D., \\ Toshiyuki HATA, M.D., Manabu KITAO, M.D. \\ Department of Obstetrics and Gynecology, Shimane Medical University \\ (Received 11 June 1990, Accepted 9 July 1990)
}

\begin{abstract}
Fetal intracranial arterial velocimetries were serially performed on 40 pregnant women with regular menstrual cycle, at 28-40 weeks of gestation, using color and pulsed Doppler ultrasound. The change in fetal intracranial arterial hemodynamics was based on the calculation of resistance index (RI). RI in the anterior cerebral artery (ACA), middle cerebral artery (MCA) and posterior cerebral artery (PCA) showed significant changes with advancing gestational age, respectively. There was no signficant difference between the RI values in the ACA and MCA from 28 weeks to term. The RI in the PCA was significantly lower than that in the ACA and MCA, respectively, from 28 weeks to term $(\mathrm{p}<0.001)$. This color and pulsed Doppler ultrasound assessment of fetal intracranial arterial blood flow provides a useful foundation for elucidating normal intracranial hemodynamics and wiil aid in avoiding misinterpretations of the different intracranial arteries.
\end{abstract}

Key words : Color and pulsed Doppler ultrasound, Intracranial arterial hemodynamics, Fetus, Assessment.

\section{1. 緒}

近年，超音波ドプラ法を用いた胎児頭蓋内血流計測が 盛んに行なわれるようになり，その結果，胎児頭蓋内血 流動態の妊娠週数に伴った変化や胎児仮死における特徴 的な血流動態が報告されるようになってきた ${ }^{1)-4)}$. 現在 行われている胎児頭蓋内血流計測はBモード画像上で胎 児頭部横断面を描出し, 中脳前方でWillis動脈輪の拍動 が認められる部位にパルスドプラ法のサンプリングポイ ントを設定することにより，血流速度波形を記録してい る1)-4). しかしながら, Willis動脈輪の拍動が認められる
部位では前大脳動脈, 中大脳動脈, 後大脳動脈などが非 常に接近して存在していて，どの動脈から得られた血流 速度波形なのか明らかでないという問題も提起されてい

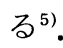

今回，カラードプラ法を用いて胎児頭蓋内血管を正確 に同定し，胎児頭蓋内血流動態に関する詳細な検討を行 ない，若干の知見を得たので報告する.

\section{2. 研究対象および方法}

妊娠28週から40週までの合併症のない月経周期の規則 的な妊婦40例を対象としてのべ134回の超音波検查を施

秦＼cjkstart幸洁：干693 出雲市塩冶町89-1 島根医科大学医学部産科婦人科学教室

Kohkichi HATA : Department of Obstetrics and Gynecology, Shimane Medical University, 89-1, Enya-cho, Izumo 693. 


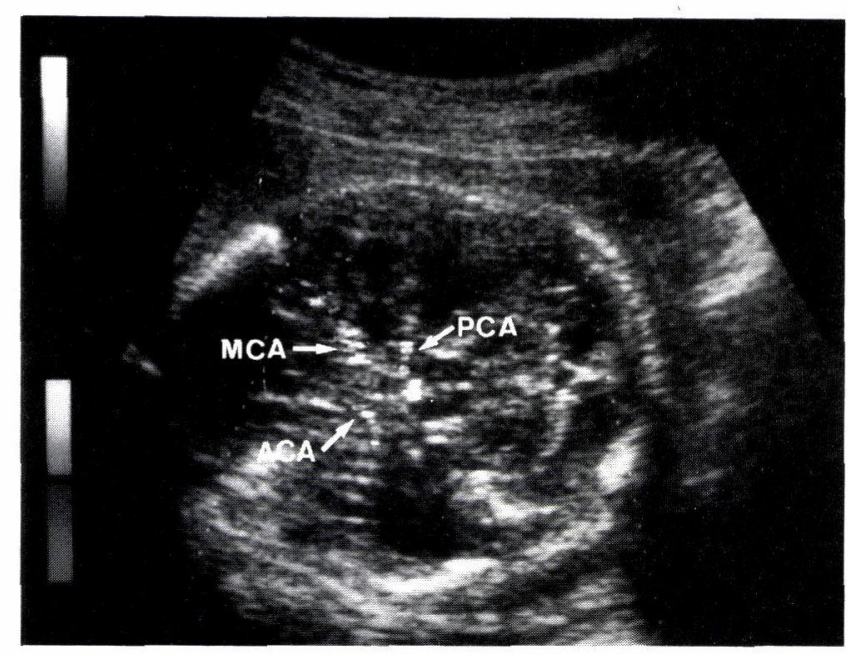

Fig. 1 Doppler color flow mapping of the circle of Willis.

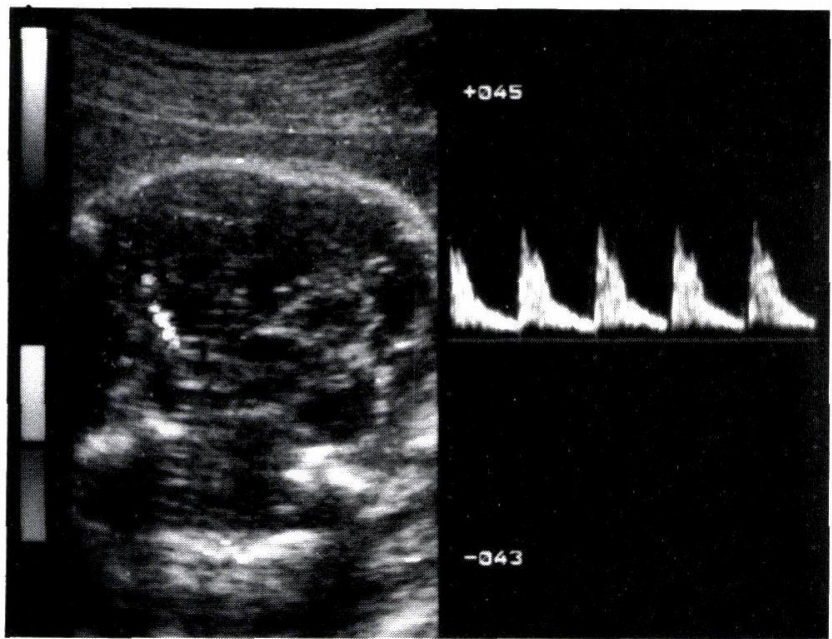

Fig. 2b Doppler color flow mapping of the middle cerebral artery and its velocity waveform.

行した。

カラードプラ法を用い, 児頭横断面で中脳前方のWillis動脈輪の位置を確認して(Fig.1)，プローブの角度を調 節して, 前大脳動脈 (以下ACAと略), 中大脳動脈 (以下 $\mathrm{MCA}$ と略), 後大脳動脈 (以下PCAと略)の走行をそれぞ れ力ラー表示により同定した. ACAが前床状突起の上方 で前内方へ曲がる部位，MCAがSylvius裂を走行する部 位，PCAが大脳脚に沿って後外側に向かう部位にパルス ドプラ法のサンプリングポイントを設定し，血流速度波 形を記録した(Fig. 2)。

血流速度波形の評価には angle-independent $の$ resistance index (以下RIと略) ( $\mathrm{RI}=\mathrm{A}-\mathrm{B} / \mathrm{A}, \mathrm{A}$ :max systolic

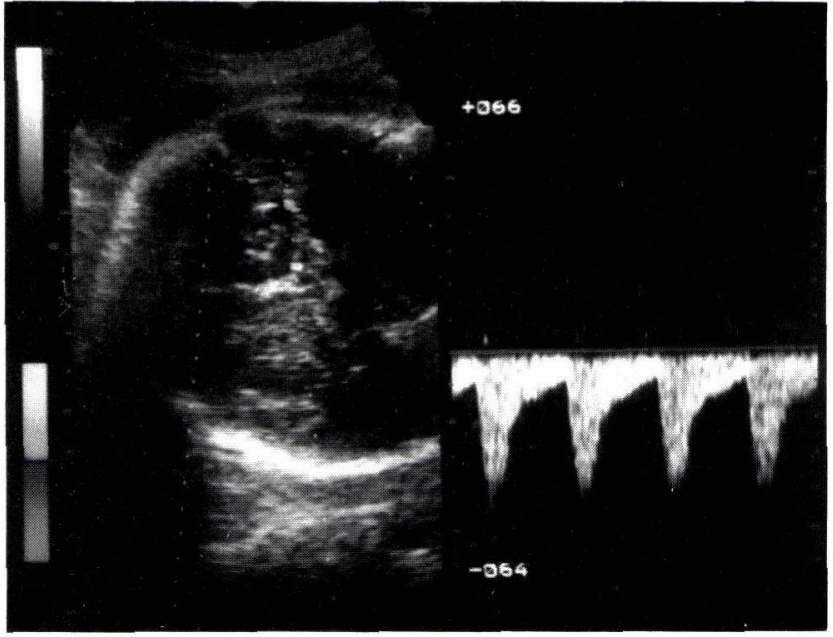

Fig. 2a Doppler color flow mapping of the anterior cerebral artery and its velocity waveform.

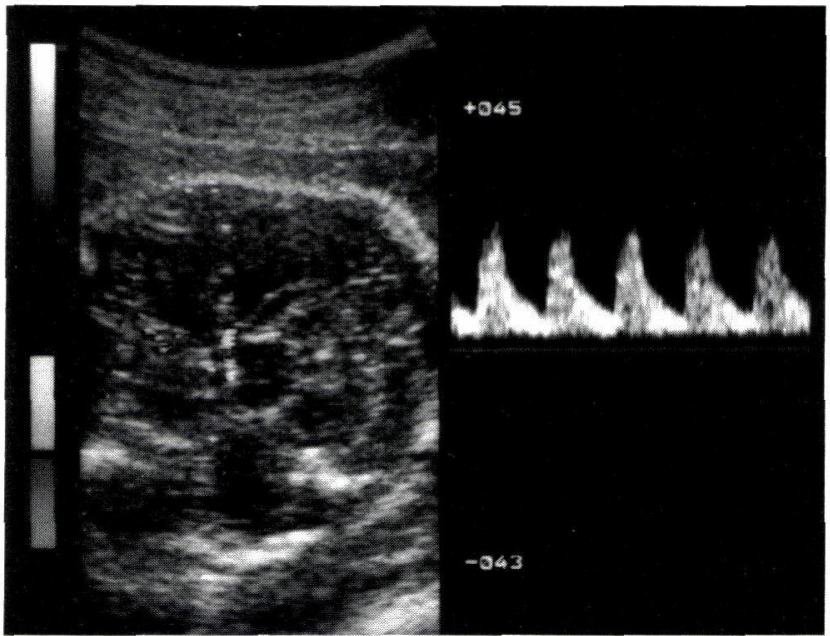

Fig. 2c Doppler color flow mapping of the posterior cerebral artery and its velocity waveform.

frequency, B:max end-diastolic frequency)を用いた(Fig. 3).また，統計学的検討は分散分析，paired t-test拉よび unpaired t-test 使用した。

使用した超音波診断装置はAloka SSD-870 (3.5 MHz) およびAloka SSD-680(3.5 MHz)である.

\section{3. 結 果}

ACA，MCA，PCAのRI值をTable 1に示す。ACA, $\mathrm{MCA}, \mathrm{PCA}$ とも RIは妊娠週数の進行に伴い, 有意に変化 し，妊娠末期では妅娠28～29週に比べて有意に低下した (Fig. 4).また，妊娠28週以降ACAとMCAのRIにおける 有意差は認められなく, PCAのRIはACAおよびMCAの 


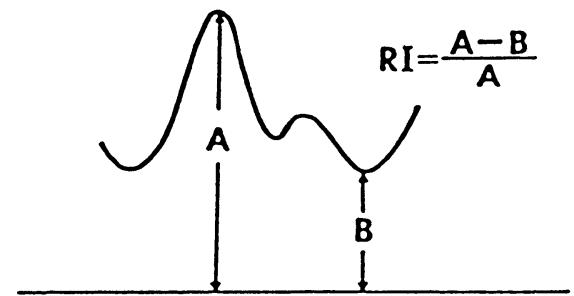

Fig. 3 Diagrammatic representation of resistance index.

RIに比べて有意に低值であった(Fig. 4).

\section{4. 考 察}

Bモード・パルスドプラ複合装置を用いた胎児頭蓋内 血流計測では, 胎児中脳前方で動脈性拍動が認められる 部位にパルスドプラ法のサンプリングポイントを設定し て血流速度波形を記録している1)-4). このようにして得 られた血流は, 内頸動脈 ${ }^{133}$ (以下ICAと略), $\mathrm{ACA}^{2)}$ ある いは $\mathrm{MCA}^{4)}$ 血流であるとされていて，報告者により 様々である. 解剖学的にみて, 中脳前方にあるWillisの動 脈輪はACA，MCA，PCAおよびICAの末梢部分が非常 に接近して存在していて，Bモード・パルスドプラ複合装 置を用いても，それぞれの血管を区別するのは不可能で あると考えられる5).さらに，最近Mariら ${ }^{6}$ はMCA と ACAおよびICAの pulsatility indexの間には有意差が認 められたことを報告しており，胎児頭蓋内血管を個別に 同定することの重要性が明らかとなってきた。 カラード プラ法を用いるとWillisの動脈輪は明瞭にカラーフロー マッピングできる(Fig. 1)ので，われわれはカラードプラ 法を用いて胎児頭蓋内血管を正確に同定し，胎児頭蓋内 血流動態に関する詳細な検討を試みた。

Table 1 Resistance index values from fetal intracranial arteries.

\begin{tabular}{cccc}
\hline $\begin{array}{c}\text { gestational age } \\
\text { (weeks)(N) }\end{array}$ & ACA & MCA & PCA \\
\hline $28 \sim 29(11)$ & $0.85 \pm 0.03$ & $0.84 \pm 0.03$ & $0.74 \pm 0.05$ \\
$30 \sim 31(14)$ & $0.84 \pm 0.05$ & $0.84 \pm 0.05$ & $0.75 \pm 0.05$ \\
$32 \sim 33(17)$ & $0.82 \pm 0.05$ & $0.84 \pm 0.05$ & $0.75 \pm 0.06$ \\
$34 \sim 35(27)$ & $0.81 \pm 0.05$ & $0.81 \pm 0.04$ & $0.73 \pm 0.04$ \\
$36 \sim 37(40)$ & $0.79 \pm 0.06$ & $0.79 \pm 0.05$ & $0.71 \pm 0.04$ \\
$38 \sim 40(25)$ & $0.76 \pm 0.06$ & $0.76 \pm 0.08$ & $0.68 \pm 0.08$ \\
\hline
\end{tabular}

Results are Mean \pm SD

ACA: anterior cerebral artery, $\mathrm{F}(5,128)=7.16, p<0.01$ MCA: middle cerebral artery, $\mathrm{F}(5,128)=7.15, p<0.01$ PCA: posterior cerebral artery, $\mathrm{F}(5,128)=5.89, p<0.001$

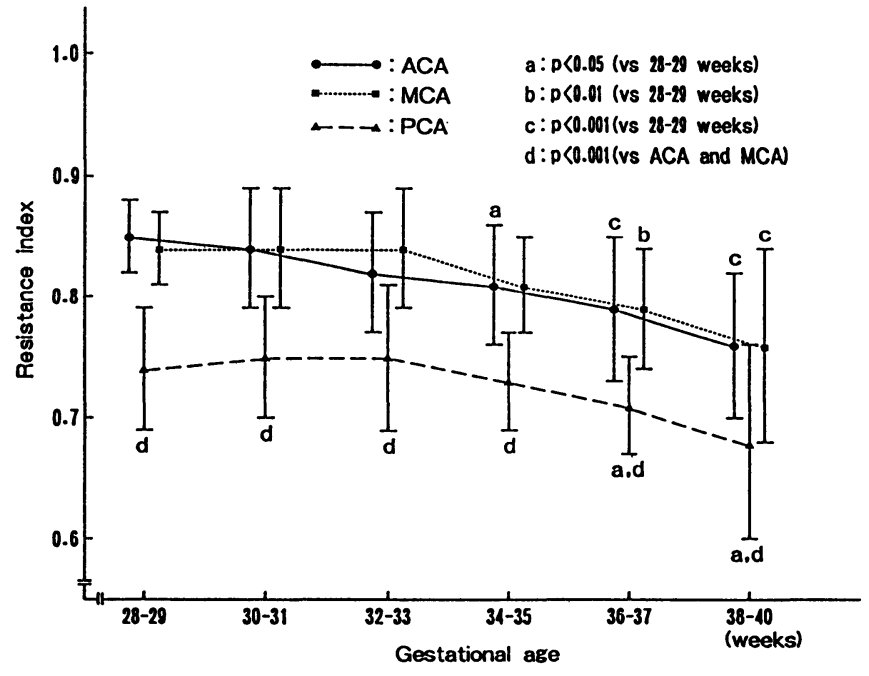

Fig. 4 Transition of fetal intracranial arterial resistance index.

ACA, MCA，PCAともRIは妊娠週数の進行に伴い, 有意に変化し，妊娠末期では妊娠28～29週に比べて有意 に低下した. 胎生初期, 大脳半球の表面は比較的平滑で ある. その後, 妊娠の進行とともに脳は絶えず成長を続 け, 胎生終末期には, 大脳半球の表面はきわめて急速な 発育を遂げるので，その表面には，溝で分けられた多数 の大脳回(gyrus) と大脳溝(sulcus)が現われる7). 妊娠末期、 でのACA，MCA，PCAのRIの有意な低下は，このよう な大脳半球の成長に伴った胎児頭蓋内血管床の増加によ るものと考えられる. ACA, MCAはICAの末梢での分岐 である. 妊娠28週以後両者のRIには有意差が認められな かった.このことはACAとMCAは同じ血管から由来し ていて, 末梢血管抵抗および血管床の増減に差がないこ とを示唆すると思われる. PCAは脳底動脈が橋上部の前 方で左右に分岐したものである. 後交通動脈(以下PCom と略）は視神経の上方でICAより分岐しPCAに吻合す る.PComは小児や成人では比較的低形成であるが胎生 期では太い8). PCAのRIはACAおよびMCAのRIに比べ て有意に低值であったが，この所見は胎児ではICAから PCAへとPComを通ってかなりの血流がシャントするこ とによるものではないかと推察される。しかしながら, 今回の検討ではPComの血流はほとんど検出できなかっ た.これは, PComが比較的短いこと, また，その走行が プローブに対してほぼ垂直であることによるものである. 従来の研究によると, 胎児低酸素症では脳動脈の拡張 末期血流は増加し, 低酸素症を補うために脳血流を増加 
させようとする“brain-sparing effect”がヒト胎児に存在 すると報告されてきだ)-4). しかしながら，それらはBモ ード・パルスドプラ複合装置を用いた検討であり，PCA の血流を他の頭蓋内血管の血流として捉えていた可能性 もある。その場合, 正常胎児の頭蓋内血流動態を異常と 過大評価することになる. 今回のカラードプラ法を用い た検討より胎児脳動脈は，同定する血管により得られる 血流速度波形が異なることが明らかとなった. 今後, 胎 児頭蓋内血流速度を記録する際には，カラードプラ法を 用いた正確な血管の同定が必要であると考えられる.

\section{5. 結 語}

カラードプラ法を用いて胎児頭蓋内血管を正確に同定 し，胎児頭蓋内血流動態に関する詳細な検討を行なった。 その結果, 胎児頭蓋内動脈は, 同定する血管により得ら れる血流速度波形が異なることが明らかとなった。

本論文の要旨は第34回アメリカ超音波医学会議 (1990 年3月, New Orleans, LA）および第9回日本脳・神経超 音波研究会（1990年4月，京都）にて発表した.

\section{文 献}

1) Wladimiroff JW, Tonge HM, Stewart PA. Doppler ultrasound assessment of cerebral flow in the human fetus. $\mathrm{Br} \mathbf{J}$ Obstet Gynaecol 1986; 93: 471-475.

2) Arebeille $\mathrm{Ph}$, Roncin A, Berson M, Patat F, Pourcelot L. Exploration of the fetal cerebral blood flow by duplex Dopplerlinear array system in normal and pathological pregnancies. Ultrasound Med Biol 1987; 13: 329-337.

3) Wladimiroff JW, Van Wijngaard JAGW, Degani S, Noordam MJ, Van Eyck J, Tonge HM. Cerebral and umbilical arterial blood flow velocity waveforms in normal and growth-retarded pregnancies. Obstet Gynecol 1987; 69: 705-709.

4) Woo JSK, Liang ST, Lo RLS, Chan FY. Middle cerebral artery Doppler flow velocity waveforms. Obstet Gynecol 1987; 70: 613-616.

5) Kurjak A, Alfirevic Z, Miljan M. Conventional and color Doppler in the assessment of fetal and maternal circulation. Ultrasound Med Biol 1988; 14: 337-354.

6) Mari G, Moise KJ Jr, Deter RL, Kirshon B, Carpenter RJ, Huhta JC. Doppler assessment of the pulsatility index in the cerebral circulation of the human fetus. Am $\mathbf{J}$ Obtet Gynecol 1989; 160: 698-703.

7) Moore KL. The developing human (3rd ed). New York: George Thieme Verlag Stuttgart, 1982: 479.

8) Huber P. Cerebral angiography (2nd ed). Philadelphia: WS Saunders Company, 1982: 585. 